\title{
Measuring chronic stress exposure incorporating the active and healthy ageing (AHA) concept within the cross- sectional Bern cohort study 2014 (BeCS-14)
}

Petra Stute ${ }^{1 *}$ (D), Marion Anker ${ }^{2}$, Laura Hollenstein ${ }^{3}$, Michael von Wolff ${ }^{1}$, Norman Bitterlich ${ }^{4}$, Florian Meissner ${ }^{5}$ and Dagmar Poethig ${ }^{6}$

\begin{abstract}
The aim of the study was to represent chronic stress exposure by a complex generic Active and Healthy (AHA) diagnostic assessment tool incorporating ICF. This is a single-centre, cross-sectional, observational, non-interventional, non-randomized trial in University based women's hospital, division of Gynecological Endocrinology and Reproductive Medicine. All participants followed a standardized, holistic battery of biopsychosocial assessments consisting of bio-functional status (BFS), bio-functional age (BFA) and the questionnaire for chronic stress exposure (TICS). 624 non-pediatric, non-geriatric subjects were recruited in the BeCS-14 cohort. The mean difference between chronological age and BFA was 7.8 \pm 8.0 year equivalents. The mean stress level score assessed by SSCS was 13. 2 with $45.4 \%$ being exposed to above average stress intensity. 22 BFS items (14 objective, 7 subjective) significantly correlated with chronic stress exposure (TICS-SSCS). The constructed sum score composed of SOC_L9 and complaint questionnaire (physical and emotional wellbeing) represented chronic stress exposure best (pearson-correlation value $0.564, p<0.0001)$. Higher chronic stress exposure was associated with bio-functional pro-aging (less vitality) in both sexes. In conclusion, chronic stress is accepted as a major risk factor for developing non-communicable diseases (NCD). Our ICF compatible, complex, generic BFS/BFA assessment tool reflects chronic stress exposure and may be applied in various health care settings, e.g., in health promotion and prevention of NCDs.
\end{abstract}

Keywords: Chronic stress, European innovation partnership on active and healthy ageing (EIP-AHA), Bio-functional status, Bio-functional age, Bern cohort study 2014

\section{Introduction}

The concept of Active and Healthy Aging (AHA) incorporates biological aging, active aging as well as changes in psychological and social wellbeing [1] that may support survival to old age, delay in the onset of non-communicable diseases (NCD) and optimal functioning for the maximal period at individual levels, body systems and cells. The corresponding conceptual AHA framework [1] includes several items such as functioning (individual capability and underlying body systems),

\footnotetext{
* Correspondence: petra.stute@insel.ch

'Department of Gynecologic Endocrinology and Reproductive Medicine, University Clinic of Obstetrics and Gynecology, Inselspital Bern, Effingerstrasse 102, 3010 Bern, Switzerland

Full list of author information is available at the end of the article
}

wellbeing, activities and participation, and diseases including NCD.

Chronic stress defined as maladaption to repeatedly occuring stressors due to the absence of adaequate coping mechanisms [2] has an impact on AHA as chronic activation of stress regulating systems, e.g. the sympathetic nervous system and the hypothalamic-pituitary-adrenal (HPA) axis, are associated with an increased risk for several NCD such as cardiovascular diseases [3], gastrointestinal diseases [4], diabetes mellitus, osteoporosis, immunodeficiency [5], sleeping disorders [6] and chronic pain [7], respectively.

We recently fitted our bio-functional status (BFS) and bio-functional age (BFA) assessment tool into a theoretical model incorporating both, the ICF and AHA concept, 
resulting in a complex generic AHA assessment diagnostic tool [8]. This complex generic AHA assessment diagnostic tool meets the EIP-AHA requirements for a diagnostic AHA instrument [9] such as applicability to health and disease across age stages (non-pediatric and non-geriatric lifetime), easy, partly self- and proxy administration, and accordance with the ICF of the WHO. As chronic stress is one major factor influencing AHA we postulate that our complex generic AHA assessment diagnostic tool also reflects chronic stress exposure. To test this assumption, we applied the BFS/BFA assessment tool together with the validated questionnaire for chronic stress exposure, TICS, within our Bern Cohort Study 2014 (BeCS-14) and aimed to generate a score from selected BFS items to represent chronic stress exposure not only subjectively [10] but also objectively.

\section{Material and methods Study population}

German speaking women and men aged 18 to 65 were recruited between 04.03.2012 and 04.07.2014 at the Department of Obstetrics and Gynecology, Inselspital Bern, Switzerland. Recruitment was performed by the principle investigator (PS), the study nurse (JDW) and fourteen doctoral students of the medical school, university Bern, via personal contact (patients, collegues, family, friends) and online advertisement (internet, intranet Inselspital Bern, social media). Exclusion criteria were pregnancy, acute diseases (e.g. fever, acute pain syndrome), and illiteracy. The study protocol was approved by the cantonal ethics committee Bern (ref.-Nr. KEK-BE: 023112), and written informed consent was obtained from each participant

\section{Study design}

The study design has been described before [8]. Briefly, this was a single-centre, cross-sectional, observational, non-interventional trial. All participants within BeCS-14 followed a standardized battery of assessments consisting of a personal and family history, bio-functional status (BFS) and bio-functional age (BFA), and validated questionnaires for depression and anxiety (HADS) [11], health-related quality of life (SF-36) [12] and chronic stress (TICS) [13], respectively. Participants were further divided into four subgroups for additional assessments addressing "nutrition" by AD-EVA [14] and PATEF [15], "employees' health" by IMPULS [16], "stress" by heart rate variability [17] and "cognition" by IGD [18]. The assessments relevant for this publication are further described in section 2.3.

\section{Assessment procedures} Personal and family history

Briefly, we assessed age, social status (partnership, having children, satisfaction with relationship and sex life), life style (alcohol, tobacco, sport, sleep), and job status (highest educational degree, current field of work, job position, working hours, monthly gross income, presenteeism, absenteeism). Personal and family history further comprised information about malignancy, cardiovascular disease, breathing disorder, abdominal and urogenital disease, metabolic disorder, skin and/or hair disease, neuromuscular and psychiatric disorder as well as bone and joint disease.

\section{Bio-functional status (BFS) and bio-functional age (BFA)}

The BFS was assessed by a comprehensive test battery developed by Poethig et al. and reported by others [19-21], respectively, which is commercially available via vital.services (https://www.microsoft.com/de-de/p/biofunktionaler-status/9wzdncrd38qr). The test battery comprises holistic characteristics from physical, mental-emotional and social areas that fit into a complex theoretical model incorporating the ICF and AHA concept (Table 1). The test battery for BFS assessment is a validated age- and sex-specific tool (objectivity 0.96 , reliability 0.93 , females age validity: total age correlation $85.2 \%$; total age commonality in the main factor 76.3\%). The BFA is based on a sex-specific regression and factor analysis of functional age [19-22].

\section{Trier inventory for the assessment of chronic stress (TICS)}

The TICS is a standardised, validated questionnaire (Cronbach alpha 0.9) [23]. It measures nine aspects of chronic stress, e.g., work overload, social overload, pressure to perform, work discontent, excessive demands at work, lack of social recognition, social tensions, social isolation and chronic worrying. Each of the 57 items is rated on a five-point rating scale assessing how often one has experienced a certain situation within the past 3 months $(0=$ never, $1=$ rarely, $2=$ sometimes, $3=$ often, $4=$ very often). In addition, a standardised screening scale for chronic stress (SSCS) represents a global value for chronic stress exposure within the past 3 months. It covers five out of the nine chronic stress domains. The total score ranges from 0 to 48 points providing three subcategories of perceived chronic stress intensity: below average stress ( 0 to 11 points), above average stress (12 to 22 points) and extreme stress ( $>22$ points) [24]. Reference values are provided for three age categories but not for sex.

\section{Statistical analysis}

Statistical analysis was performed by applying SPSS (Statistical Package for the Social Sciences) for Mac (Version 22.0). Data have been analysed descriptively, by t-test and chi-square test, respectively. For correlation analysis, the two-sided Pearson product-moment correlation coefficient was used. Statistical significance was defined as $p<0.05$. 
Table 1 Single items of the bio-functional status (BFS) and calculated bio-functional age (BFA)

\begin{tabular}{|c|c|c|c|c|c|}
\hline Bio-functional status (BFS) item & $\mathrm{N}$ & Mean & SD & 5th-95th percentile & Min - Max \\
\hline \multicolumn{6}{|l|}{ Physical parameters } \\
\hline Systolic blood pressure [mmHg] & 612 & 118.9 & 13.8 & $99.0-144.0$ & $82.0-169.0$ \\
\hline Diastolic blood pressure [mmHg] & 612 & 74.4 & 10.6 & $58.7-93.0$ & $47.0-107.0$ \\
\hline Resting heart rate $(\mathrm{p} 0)[\mathrm{n} / \mathrm{min}]$ & 607 & 68.3 & 10.4 & $52.4-86.0$ & $42.0-107.0$ \\
\hline Pulse rate difference $(\Delta p)$ & 600 & 121.1 & 18.4 & $92.0-152.0$ & $68.0-204.0$ \\
\hline Performance time $[\mathrm{sec}]$ & 600 & 24.0 & 6.0 & $16.6-34.4$ & $12.1-63.0$ \\
\hline Pulse performance index (PPI) $[\Delta \mathrm{p} /$ performance time $]$ & 600 & 2.3 & 0.1 & $1.0-4.1$ & $0.1-8.3$ \\
\hline Vital capacity [l] & 592 & 4.2 & 1.2 & $2.5-6.7$ & $1.7-7.5$ \\
\hline Vital capacity, women [\%] & 441 & 106.8 & 18.9 & $73.5-136.6$ & $43.0-158.7$ \\
\hline Vital capacity, men [\%] & 150 & 110.8 & 18.1 & $78.9-137.1$ & $54.5-153.0$ \\
\hline Hand grip strength, left [KP] & 598 & 33.2 & 18.0 & $9.0-70.0$ & $1.0-70.0$ \\
\hline Hand grip strength, right [KP] & 602 & 38.4 & 18.1 & $14.0-70.0$ & $1.0-90.0$ \\
\hline Hand grip strength, both sides [KP] & 600 & 71.5 & 35.1 & $22.0-140.0$ & $2.0-140.0$ \\
\hline Body cell mass (\%) & 587 & 40.8 & 4.6 & $32.9-48.1$ & $28.1-55.0$ \\
\hline Body cell mass - active cell mass [kg] & 587 & 27.6 & 5.0 & $22.0-37.7$ & $19.5-48.5$ \\
\hline Body cell mass - body water [kg] & 587 & 35.1 & 6.4 & $28.0-47.9$ & $24.8-61.8$ \\
\hline Body cell mass - lean body mass [kg] & 587 & 47.9 & 8.7 & $38.2-65.4$ & $33.8-84.5$ \\
\hline Fat mass (\%) & 587 & 29.3 & 8.0 & $16.4-42.9$ & $4.8-51.4$ \\
\hline Fat mass $[\mathrm{kg}]$ & 587 & 20.5 & 8.4 & $10.3-36.1$ & $1.9-56.5$ \\
\hline BIA RC 50 (Ohm) & 587 & 608.7 & 85.8 & $465.0-744.0$ & $368.0-869.0$ \\
\hline BIA XC 50 (Ohm) & 587 & 63.2 & 10.8 & $47.0-80.0$ & $30.0-116.0$ \\
\hline Teeth status - decayed, missing or filled teeth (n) & 616 & 9.9 & 8.1 & $0.0-28.0$ & $0.0-32.0$ \\
\hline Body weight (kg) & 617 & 68.3 & 13.1 & $51.0-94.0$ & $36.0-120.0$ \\
\hline Body height $(\mathrm{cm})$ & 617 & 169.8 & 8.7 & $157.0-185.0$ & $150.0-195.0$ \\
\hline Body mass index $[\mathrm{kg} / \mathrm{m} 2]$ & 617 & 23.7 & 4.0 & $18.7-31.2$ & $12.3-47.0$ \\
\hline \multicolumn{6}{|l|}{ Sensory physiology and psychomotor parameters } \\
\hline Vision left [\%] & 368 & 81.2 & 30.1 & $10.0-100.0$ & $0.0-100.0$ \\
\hline Vision right [\%] & 367 & 81.0 & 29.2 & $12.0-100.0$ & $0.0-100.0$ \\
\hline Hearing acuity -HV1024 left (Db) & 551 & 16.0 & 8.7 & $5.0-30.4$ & $0.0-100.0$ \\
\hline Hearing acuity -HV1024 left (\%) & 551 & 1.6 & 2.5 & $0.0-5.40$ & $0.0-30.0$ \\
\hline Hearing acuity -HV1024 right (Db) & 551 & 17.5 & 8.6 & $7.0-30.0$ & $0.0-77.0$ \\
\hline Hearing acuity -HV1024 right (\%) & 551 & 2.0 & 2.8 & $0.0-5.4$ & $0.0-27.2$ \\
\hline Hearing acuity -HV2048 left (Db) & 548 & 17.0 & 9.9 & $5.0-36.0$ & $0.0-100.0$ \\
\hline Hearing loss left 2048 Hz [\%] & 548 & 2.8 & 4.0 & $0.2-9.8$ & $0.0-40.0$ \\
\hline Hearing acuity -HV2048 right (Db) & 549 & 18.3 & 10.1 & $6.0-37.5$ & $0.0-88.0$ \\
\hline Hearing loss right $2048 \mathrm{~Hz}$ [\%] & 549 & 3.2 & 4.5 & $0.2-11.4$ & $0.0-39.2$ \\
\hline Hearing acuity -HV4096 left (Db) & 548 & 18.0 & 13.6 & $3.0-44.0$ & $0.0-100.0$ \\
\hline Hearing loss left 4096 Hz [\%] & 548 & 1.4 & 2.3 & $0.1-6.4$ & $0.0-15.0$ \\
\hline Hearing acuity -HV4096 right (Db) & 549 & 18.5 & 13.4 & $3.0-45.5$ & $0.0-100.0$ \\
\hline Hearing loss right $4096 \mathrm{~Hz}$ [\%] & 549 & 1.4 & 2.4 & $0.1-6.4$ & $0.0-15.0$ \\
\hline Hearing acuity -HV512 left (Db) & 551 & 14.9 & 7.5 & $5.0-26.0$ & $0.0-100.0$ \\
\hline Hearing acuity -HV512 left (\%) & 551 & 1.8 & 2.7 & $0.2-4.9$ & $0.0-40.0$ \\
\hline Hearing acuity -HV512 right (Db) & 551 & 18.1 & 7.7 & $8.0-30.0$ & $0.0-79.0$ \\
\hline Hearing acuity -HV512 right (\%) & 551 & 2.8 & 3.0 & $0.4-7.2$ & $0.0-35.8$ \\
\hline
\end{tabular}


Table 1 Single items of the bio-functional status (BFS) and calculated bio-functional age (BFA) (Continued)

\begin{tabular}{|c|c|c|c|c|c|}
\hline Bio-functional status (BFS) item & $\mathrm{N}$ & Mean & SD & 5th-95th percentile & Min - Max \\
\hline Start rate $[\mathrm{Hz}]$ & 608 & 6.6 & 0.9 & $5.2-8.1$ & $2.0-9.2$ \\
\hline Test motivation $[\mathrm{Hz}]$ & 608 & 5.9 & 0.7 & $4.9-6.9$ & $2.3-8.4$ \\
\hline Tapping - basic rate, part $3(\mathrm{~Hz})$ & 608 & 6.1 & 0.7 & $4.8-7.0$ & $0.9-8.4$ \\
\hline Psychomotor endurance $[\mathrm{Hz}]$ & 608 & 5.9 & 0.7 & $5.1-7.3$ & $0.1-8.2$ \\
\hline Viseomotor coordination ability (mistakes) [n] & 606 & 13.2 & 7.0 & $3.0-26.0$ & $1.0-39.0$ \\
\hline Viseomotor coordination ability (time) [sec] & 606 & 29.8 & 14.3 & $12.8-57.9$ & $6.5-103.2$ \\
\hline \multicolumn{6}{|l|}{ Cognitive and mental parameters } \\
\hline Optical reaction time [msec] & 613 & 277.3 & 37.4 & 221.7-339.3 & 195.0-460.0 \\
\hline Acoustical reaction time [msec] & 614 & 283.4 & 40.7 & $217.0-347.3$ & $176.0-475.0$ \\
\hline Pursuing reaction time [msec] & 615 & 68.4 & 27.7 & $31.0-118.0$ & $19.0-210.0$ \\
\hline Verbal reaction time $[\mathrm{sec}]$ & 612 & 10.8 & 1.8 & $8.2-14.0$ & $7.2-19.9$ \\
\hline Cognitive reaction time [sec] & 612 & 12.9 & 2.3 & $9.8-16.8$ & $7.9-24.0$ \\
\hline Cognitive switching capability [sec] & 612 & 22.7 & 7.7 & $14.6-34.6$ & $10.4-113.0$ \\
\hline Ability to concentrate (mistakes) [n] & 611 & 1.5 & 2.0 & $0.0-6.0$ & $0.0-14.0$ \\
\hline Ability to concentrate (time) [sec] & 611 & 121.1 & 37.9 & 72.9-188.7 & $52.1-320.4$ \\
\hline Orientation capability [n] & 614 & 50.0 & 14.2 & $38.0-71.0$ & $30.0-181.0$ \\
\hline Strategic thinking $[\mathrm{sec}]$ & 614 & 153.0 & 67.3 & $87.4-261.0$ & $64.3-779.9$ \\
\hline Memory performance [n] & 614 & 95.2 & 21.0 & $85.0-125.3$ & $30.0-313.0$ \\
\hline Change over capability [sec] & 614 & 1.05 & 0.4 & $0.6-1.6$ & $0.5-6.6$ \\
\hline \multicolumn{6}{|l|}{ Emotional-social parameters } \\
\hline Stress disposition [score] & 464 & 27.3 & 5.3 & $18.0-35.8$ & $10.0-40.0$ \\
\hline Social dominance [score] & 464 & 26.7 & 5.2 & $17.0-35.0$ & $9.0-40.0$ \\
\hline Social power [score] & 464 & 16.1 & 4.8 & $9.0-25.0$ & $6.0-35.0$ \\
\hline Stress exposition [score] & 464 & 30.8 & 5.2 & $22.0-38.8$ & $12.0-42.0$ \\
\hline Physical wellbeing [score] & 615 & 3.4 & 3.9 & $0.0-11.2$ & $0.0-24.0$ \\
\hline Emotional wellbeing [score] & 615 & 1.7 & 2.6 & $0.0-8.0$ & $0.0-14.0$ \\
\hline Complaint questionnaire - physical and emotional wellbeing [score] & 615 & 5.1 & 5.6 & $0.0-17.0$ & $0.0-32.0$ \\
\hline Social activity / leisure [score] & 615 & 52.6 & 13.7 & $31.2-74.5$ & $12.0-86.0$ \\
\hline Social activity / duties [score] & 615 & 90.3 & 11.0 & $70.5-106.3$ & $50.0-118.0$ \\
\hline Sense of coherence [score] & 346 & 51.1 & 7.0 & $37.0-61.0$ & $29.0-63.0$ \\
\hline \multicolumn{6}{|l|}{ Age parameters } \\
\hline Chronological age [years] & 617 & 39.6 & 14.8 & - & $20.0-78.7$ \\
\hline Bio-functional age (BFA) [years] & 315 & 44.1 & 8.6 & - & $20.1-73.7$ \\
\hline difference_Age_BFA_Index (chronological - bio-functional age) & 316 & 7.8 & 8.0 & - & $-19.4-29.6$ \\
\hline
\end{tabular}

Abbreviations: BIA Bioelectrical impedance analysis, Xc Reactance (capacitive resistance), Rc Resistance (ohmic resistance)

\section{Results}

\section{Characteristic of the cohort}

\section{Age, lifestyle, social and job status}

In total, 624 participants $(73.7 \%$ female, $26.3 \%$ male) were recruited, mainly $(79.8 \%)$ via personal contact. Mean age was $39.5 \pm 14.9$ years. For BFA assessment, age 35 is an accepted threshold; 313 participants (50.2\%) were above age $35.36 .2 \%$ of participants reported regular alcohol consumption at least twice a week. $37.2 \%$ had at least one drink per day. In contrast, the majority was never-smoker (64.7\%) and physically active (till sweating) $(75.2 \%)$ at least once a week. The majority of participants was living in a partnership (74.8\%), almost two thirds (65.4\%) were childless, whereas one in four participants had at least two children (27.6\%). About half of participants $(53.8 \%)$ had a degree from university or advanced technical college, respectively. One in five participants $(20.2 \%)$ had a degree from vocational business school. Most participants (37.7\%) worked in the social field with $52.1 \%$ being employees and $23.7 \%$ students, 
respectively. Job occupation was at least $50 \%$ in more than half $(68.6 \%)$ of participants, and at least $90 \%$ in $41.8 \%$. The monthly gross income was less than 5000 Swiss Francs for $49.4 \%$.

\section{Personal and family history}

The prevalence of being disease free was $18.8 \%(n=177)$. Life threatening events were reported by 11 participants (myocardial infarction $n=2$; stroke $n=4$; pulmonary embolism $n=5$ ). The prevalence of a positive family history varied and was more than $15 \%$ for cancer $(40.2 \%)$, cardiovascular disease (hypertension 32.4\%, myocardial infarction $25.3 \%$, stroke $17.3 \%$, pulmonary embolism $6.3 \%$ ), metabolic disorder (dyslipidemia 21.6\%, diabetes mellitus $15.1 \%)$, depression (19.6\%) and osteoarthritis (20.5\%).

\section{Medication}

In the BeCS-14 cohort, 356 subjects reported use of any kind of medication ( $n=617$ reports). The major medication groups were dietary supplements $(n=177)$, sexual steroids for contraception $(n=128)$ or menopausal hormone therapy $(n=50)$, psychotropic medication $(n=52)$, analgetics $(n=59)$ and antihypertensives $(n=38)$, respectively.

\section{Bio-functional status (BFS) and bio-functional age (BFA)}

Table 1 presents the single BFS items categorized into the four subdomains 1) physical parameters, 2) sensory physiology and psychomotor parameters, 3) cognitive and mental parameters as well as 4) emotional-social parameters, respectively. In addition, chronological and the calculated BFA are provided for the whole BeCS-14 cohort. The mean difference between chronological and bio-functional age was $7.8 \pm 8.0$ year equivalents.

\section{Chronic stress exposure}

Table 2 presents the TICS subdomains and the SSCS for the whole BeCS-14 cohort. When comparing to the mean values (T50) of the reference population, the BeCS-14 cohort perceived a similar chronic stress level overall (SSCS) and in the subdomaines work overload, work discontent, lack of social recognition, social tensions and social isolation. In contrast, chronic stress by social overload seemed to be higher whereas chronic stress by pressure to perform, and chronic worrying in particular, were lower within the BeCS-14 cohort.

In BeCS-14, the mean stress level score assessed by SSCS was 13.2 being slightly higher in women (13.4) compared to men (12.5) $(p=0.189)$ (Table 3). When differentiating between stress intensity categories almost half of the BeCS-14 cohort (45.4\%) reported to be exposed to above average stress intensity with an additional $11.1 \%$ being exposed to extreme stress ( $\geq 90$ th percentile). While there was no sex-specific difference in perceived "above average "stress exposure, slightly more women $(12.1 \%)$ than men $(8.5 \%)$ reported to be exposed to extreme chronic stress $(p=0.278)$.

\section{Correlation between bio-functional status (BFS) and chronic stress exposure (TICS-SSCS)}

Overall, of all single BFS items (Table 1) 22 (14 objective, 7 subjective) showed a significant correlation with the TICS-SSCS (Table 4). They were ranked according to their strength of correlation with the sense of coherence (SOC_L9) showing the strongest correlation (rank $1 ; \mathrm{r}=-0.53, p<0.001$ ). In order to prove that potential confounding factors did not change results a partial correlation analysis was performed exemplarily (Pearson correlation for control variable "emotional wellbeing" $=-0.406$, "physical $/$ emotional wellbeing" $=-0.432$, "physical wellbeing" $=-0.487$, "BFA-Index" $=-0.543$, "social resonance" $=-0 .-491$, "social potency" $=-0.532$ ). The correlation size did not change and remained significant for all tests $(p<0.001)$. The handgrip strength of the left hand was the best objective parameter (rank 8,

Table 2 Chronic stress exposure assessed by TICS

\begin{tabular}{llllll}
\hline TICS subscale & Mean (SD) & 5th-95th percentile & Range & Maximal score possible & T50 (reference cohort) \\
\hline Screening scale (SSCS) & $13.2(7.0)$ & $3-26$ & $0-37$ & 48 & 13 \\
Work overload & $11.7(5.6)$ & $2-22$ & $0-31$ & 32 & 12.5 \\
Social overload & $9.1(4.3)$ & $2-16$ & $0-23$ & 24 & 7 \\
Pressure to perform & $15.1(6.0)$ & $5-25$ & $0-33$ & 36 & 17 \\
Work discontent & $8.7(4.7)$ & $2-17$ & $0-31$ & 32 & 9 \\
Excessive demands at work & $5.1(3.2)$ & $0-11$ & $0-18$ & 24 & 4.5 \\
Lack of social recognition & $3.9(2.9)$ & $0-10$ & $0-16$ & 16 & 4 \\
Social tensions & $4.8(3.3)$ & $0-11$ & $0-22$ & 24 & 5 \\
Social isolation & $5.5(4.1)$ & $0-13$ & $0-24$ & 24 & 5 \\
Chronic worrying & $4.7(2.9)$ & $0-10$ & $0-15$ & 16 & 14 \\
\hline
\end{tabular}

Abbreviations: SD Standard deviation, SSCS Screening scale for chronic stress, TICS Trier Inventory for the Assessment of Chronic Stress, T50 Mean value of reference cohort 
Table 3 Chronic stress intensity within the whole BeCS-14 cohort

\begin{tabular}{llll}
\hline & BeCS-14 cohort $(n=620)$ & Females $(n=456)$ & Males $(n=164)$ \\
\hline Below average stress (score $\leq 11)$ & $43.4 \%(n=269)$ & $42.5 \%(n=194)$ & $45.7 \%(n=75)$ \\
Above-average stress (score 12-22) & $45.5 \%(n=282)$ & $45.4 \%(n=207)$ & $45.7 \%(n=75)$ \\
Extreme stress (score $>$ 22) & $11.1 \%(n=69)$ & $12.1 \%(n=55)$ & $8.5 \%(n=14)$ \\
\hline
\end{tabular}

$\mathrm{r}=-0.129, p=0.002)$. Interestingly, none of the BFS category 2 (sensory physiology and psychomotor parameters) or category 3 (cognitive and mental parameters) item list had a significant correlation with SSCS-TICS, respectively. TICS-SSCS and the difference between chronological and bio-functional age were significantly negatively correlated (pearson-correlation $-0.24 ; \mathrm{p}<0.001)$. Thus, higher chronic stress exposure was associated with a pro-aging state or less vitality.

\section{Sum score}

In a next step, we aimed to construct a sum score out of those BFS items significantly correlating with the TICS-SSCS (Table 4). With the help of a sum score we intended to represent chronic stress exposure by our comprehensive BFS/BFA assessment tool. Ten out of 22 BFS items were chosen of which six were subjective (SOC_L9, complaint questionnaire: physical and emotional wellbeing, social resonance, social potency, social dominance) and four objective items (hand grip strength left and right, performance time, tapping basic rate). The other items could not be integrated in the sum score as they were not independent factors. For example, vital capacity was dependent on body weight, body height and sex, and when adjusting for those variables the significance was no longer evident (women $p=0.320$, men $p=0.601$ ).

As the scoring systems (the units measured) of the selected items were not comparable, we introduced six new categories by the means of visual classification in SPSS ranging from one ("bad "or a lot of stress) to six ("good "or little stress). For example, for sense of coherence, social resonance and stress exposition, social dominance, hand grip strength and basic tapping rate, respectively, the highest scores corresponded to the best classification group six. In contrast, for the complaint questionnaire covering emotional and physical wellbeing, social power and performance time, respectively, the lowest scores corresponded to the best classification group six (Table 5). Similar to the correlation analysis performed for the original BFS items and TICS-SSCS (Table 4) the newly introduced categories (1-6) also showed a significant correlation for each of the 10 selected BFS items with TICS-SSCS (Table 6).

Next, a first sum score was built using all 10 selected BFS items. As its pearson-correlation value was -0.411 $(p<0.0001)$ and thus inferior to the single BFS item sense of coherence (SOC_L9) (pearson-correlation value $-0.542 ; p<0.0001$ ), we constructed two more sum scores using either only the subjective BFS items (six out of the selected 10) or only the objective BFS items (four out of the selected 10), respectively. Again, the respective pearson-correlation values were -0.489 and -0.145 $(\mathrm{p}<0.0001)$ and thus inferior to the single BFS item sense of coherence (SOC_L9). Finally, we constructed a sum score combining the three most representative items (SOC_L9, complaint questionnaire: physical and emotional wellbeing). Indeed, this sum score was superior to the single BFS item sense of coherence (SOC_L9) (pearson-correlation value $0.564, \mathrm{p}<0.0001$ ).

\section{Discussion}

In the current study, we were able to demonstrate that 1) chronic stress exposure in the BeCS-14 cohort was comparable to that of the TICS reference cohort, 2) the mean difference between chronological age (CA) and bio-functional age (BFA) in BeCS-14 was 7.8 \pm 8.0 year equivalents, 3) 22 BFS items (14 objective, 7 subjective) significantly correlated with chronic stress exposure (TICS-SSCS), 4) the sum score composed of SOC_L9 and complaint questionnaire (physical and emotional wellbeing) represented chronic stress exposure best, and 5) higher chronic stress exposure was associated with bio-functional pro-aging (less vitality) in both sexes.

Indeed, the Swiss BeCS-14 cohort had some similarities with the German TICS reference cohort from 2003 in respect to number (BeCS-14 $n=624$; TICS $n=604$ ), mean age (BeCS-14 $39.5 \pm 14.9$ years; TICS $41.1 \pm 13.5$ years), civil status (living in partnership BeCS-14 74.8\%; TICS 78.8\%) and education (degree from university or advanced technical college BeCS-14 53.8\%; TICS 33.3\%) of participants, respectively [23].

In BeCS-14, bio-functional age (BFA) was lower than chronological age (CA). The difference was greater than the expected standard deviations in the age groups between 0.84 and 1.29 year equivalents $[19,22]$ meaning that on average the cohort was functionally younger than its chronological age. So far, only two cohort studies compared CA to BFA, a prospective pilot study in 36 menopausal women [25] and a cross-sectional study in 371 employees of five occupational groups [26]. In both cohorts, mean CA was comparable to (baseline) BFA. In the first study, BFA was significantly reduced (= improved) by $9.77 \%$ after 8 weeks of menopausal hormone 
Table 4 Ranked BFS parameters correlating with TICS-SSCS

\begin{tabular}{|c|c|c|c|}
\hline \multirow{2}{*}{$\frac{\text { Rank }}{1}$} & \multirow{2}{*}{$\begin{array}{l}\text { BFS parameter } \\
\text { SOC_L9: Sense of Coherence }\end{array}$} & \multicolumn{2}{|c|}{ Correlation to TICS-SSCS } \\
\hline & & Pearson-Correlation & -0.53 \\
\hline & & Sig. (2-sided) & $<0.001$ \\
\hline & & N & 344 \\
\hline \multirow[t]{3}{*}{2} & Complaint questionnaire: emotional wellbeing & Pearson-Correlation & 0.48 \\
\hline & & Sig. (2-sided) & $<0.001$ \\
\hline & & $\mathrm{N}$ & 611 \\
\hline \multirow[t]{3}{*}{3} & Complaint questionnaire: physical and emotional wellbeing & Pearson-Correlation & 0.43 \\
\hline & & Sig. (2-sided) & $<0.001$ \\
\hline & & N & 611 \\
\hline \multirow[t]{3}{*}{4} & Complaint questionnaire: physical wellbeing & Pearson-Correlation & 0.29 \\
\hline & & Sig. (2-sided) & $<0.001$ \\
\hline & & $\mathrm{N}$ & 611 \\
\hline \multirow[t]{3}{*}{5} & Giessen-Test: social resonance & Pearson-Correlation & -0.25 \\
\hline & & Sig. (2-sided) & $<0.001$ \\
\hline & & N & 460 \\
\hline \multirow[t]{3}{*}{6} & difference between chronological and bio-functional age (diff_Age_BFA_Index) & Pearson-Correlation & -0.24 \\
\hline & & Sig. (2-sided) & $<0.001$ \\
\hline & & $\mathrm{N}$ & 314 \\
\hline \multirow[t]{3}{*}{7} & Bio-functional age (BFA) & Pearson-Correlation & 0.16 \\
\hline & & Sig. (2-sided) & 0.004 \\
\hline & & $\mathrm{N}$ & 313 \\
\hline \multirow[t]{3}{*}{8} & Giessen-Test: social potency & Pearson-Correlation & 0.14 \\
\hline & & Sig. (2-sided) & 0.002 \\
\hline & & $\mathrm{N}$ & 460 \\
\hline \multirow[t]{3}{*}{9} & Hand grip strength, left $[K P]$ & Pearson-Correlation & -0.13 \\
\hline & & Sig. (2-sided) & 0.002 \\
\hline & & N & 594 \\
\hline \multirow[t]{3}{*}{10} & Body cell mass - active cell mass [kg] & Pearson-Correlation & -0.13 \\
\hline & & Sig. (2-sided) & 0.002 \\
\hline & & N & 583 \\
\hline \multirow[t]{3}{*}{11} & Body cell mass - body water [kg] & Pearson-Correlation & -0.13 \\
\hline & & Sig. (2-sided) & 0.002 \\
\hline & & N & 583 \\
\hline \multirow[t]{3}{*}{12} & Body cell mass - lean body mass [kg] & Pearson-Correlation & -0.13 \\
\hline & & Sig. (2-sided) & 0.002 \\
\hline & & $\mathrm{N}$ & 583 \\
\hline \multirow[t]{3}{*}{13} & Body height $[\mathrm{cm}]$ & Pearson-Correlation & -0.12 \\
\hline & & Sig. (2-sided) & 0.002 \\
\hline & & N & 613 \\
\hline \multirow[t]{3}{*}{14} & Giessen-Test: social dominance & Pearson-Correlation & -0.11 \\
\hline & & Sig. (2-sided) & 0.015 \\
\hline & & N & 460 \\
\hline \multirow[t]{2}{*}{15} & Performance time for 20 squats [sec] & Pearson-Correlation & 0.11 \\
\hline & & Sig. (2-sided) & 0.006 \\
\hline
\end{tabular}


Table 4 Ranked BFS parameters correlating with TICS-SSCS (Continued)

\begin{tabular}{|c|c|c|c|}
\hline \multirow[t]{2}{*}{ Rank } & \multirow[t]{2}{*}{ BFS parameter } & \multicolumn{2}{|c|}{ Correlation to TICS-SSCS } \\
\hline & & $\mathrm{N}$ & 596 \\
\hline \multirow[t]{3}{*}{16} & Hand grip strength, both hands [KP] & Pearson-Correlation & -0.11 \\
\hline & & Sig. (2-sided) & 0.006 \\
\hline & & $\mathrm{N}$ & 596 \\
\hline \multirow[t]{3}{*}{17} & Body composition measurement -BIA RC 50 [Ohm] & Pearson-Correlation & 0.10 \\
\hline & & Sig. (2-sided) & 0.014 \\
\hline & & $\mathrm{N}$ & 583 \\
\hline \multirow[t]{3}{*}{18} & Systolic blood pressure [mmHg] & Pearson-Correlation & -0.09 \\
\hline & & Sig. (2-sided) & 0.022 \\
\hline & & N & 608 \\
\hline \multirow[t]{3}{*}{19} & Hand grip strength, right [KP] & Pearson-Correlation & -0.09 \\
\hline & & Sig. (2-sided) & 0.028 \\
\hline & & N & 598 \\
\hline \multirow[t]{3}{*}{20} & Tapping - basic rate $[\mathrm{Hz}]$ & Pearson-Correlation & -0.09 \\
\hline & & Sig. (2-sided) & 0.035 \\
\hline & & $\mathrm{N}$ & 604 \\
\hline \multirow[t]{3}{*}{21} & Vital capacity [ccm/ml] & Pearson-Correlation & -0.09 \\
\hline & & Sig. (2-sided) & 0.038 \\
\hline & & N & 588 \\
\hline \multirow[t]{3}{*}{22} & Body weight [kg] & Pearson-Correlation & -0.09 \\
\hline & & Sig. (2-sided) & 0.036 \\
\hline & & $\mathrm{N}$ & 613 \\
\hline
\end{tabular}

therapy [25]. In the second study, the highest discrepancy between CA and BFA was found in the group of male managers being on average 9 years functionally younger while female office workers and nursery school teachers had a slight higher BFA compared to their CA [26]. Mental attitudes and resources towards work, occupational reward and the body fat percentage were found to be relevant predictors for the discrepancy between CA and BFA [26].
Various attempts have been made to assess chronic stress in a subjective or objective manner. Besides the questionnaire TICS [23] there are e.g. the Life Experiences Survey [27], Perceived Stress Scale [28], Stress Reactivity Scale [29] and Perceived Stress Questionnaire [30], respectively, that have all been found to correlate with TICS-SSCS.

Of our complex BFS/BFA assessment tool [8], seven subjective BFS items significantly correlated with chronic stress exposure assessed by TICS-SSCS: (1) sense of

Table 5 Selected BFS items for constructing a sum score representing chronic stress exposure

\begin{tabular}{|c|c|c|c|c|c|c|}
\hline & $6=$ good & 5 & 4 & 3 & 2 & $1=\mathrm{bad}$ \\
\hline SOCL_9 [score] & $>60$ & $56-60$ & $51-55$ & $46-50$ & $41-45$ & $<41$ \\
\hline Complaint questionnaire: emotional wellbeing [score] & 0 & 1 & 2 & 3 & 4 & $>4$ \\
\hline Complaint questionnaire: physical wellbeing [score] & 0 & $1-2$ & $3-4$ & $5-6$ & $7-8$ & $>8$ \\
\hline Social resonance [score] & $>37$ & $35-37$ & $32-34$ & $29-31$ & $26-28$ & $<26$ \\
\hline Social potency [score] & $<11$ & $11-14$ & $15-18$ & $19-22$ & $23-26$ & $>26$ \\
\hline Social dominance [score] & $>32$ & $30-32$ & $27-29$ & $24-26$ & $21-23$ & $<21$ \\
\hline Hand grip strength, left [kp] & $>52$ & $45-52$ & $37-44$ & $29-36$ & $21-28$ & $<21$ \\
\hline Hand grip strength, right [kp] & $>52$ & $45-52$ & $37-44$ & $29-36$ & $21-28$ & $<21$ \\
\hline Performance time [sec] & $>32$ & $29-28$ & $25-28$ & $21-24$ & $17-20$ & $<17$ \\
\hline Tapping - basic rate $[\mathrm{Hz}]$ & $>7.0$ & $6.6-7.0$ & $6.1-6.5$ & $5.6-6.0$ & $5.1-5.5$ & $<5.1$ \\
\hline
\end{tabular}


Table 6 Correlation between newly classified BFS items (Table 5) and TICS-SSCS. Subjective BFS parameters are presented in bolt and objective BFS parameters in cursive style

TICS-SSCS

SOC_L9 (classified)

Pearson-Correlation

Sig. (2-sided)

$\mathrm{N}$

BFB part II (classified)

Pearson-Correlation

Sig. (2-sided)

$\mathrm{N}$

BFB part I (classified)

Pearson-Correlation

Sig. (2-sided)

$\mathrm{N}$

Social resonance (classified)

Pearson-Correlation

Sig. (2-sided)

$\mathrm{N}$

Social potency (classified)

Pearson-Correlation

Sig. (2-sided)

N

Social dominance (classified)

Pearson-Correlation

Sig. (2-sided)

N

Hand grip strenght, left (classified)

Pearson-Correlation

Sig. (2-sided)

$\mathrm{N}$

Hand grip strenght,right (classified)

Pearson-Correlation

Sig. (2-sided)

N

Performance time (classified)

Pearson-Correlation

Sig. (2-sided)

N

Tapping - basic rate (classified)

Pearson-correlation

Sig. (2-sided)

$\mathrm{N}$ coherence, (2) physical and (3) emotional wellbeing ((4) combined items), (5) social resonance, (6) social potency and (7) social dominance. The BFS item sense of coherence (SOC_L9) had the strongest correlation with TICS-SSCS. According to the concept of salutogenesis by Antonovsky, sense of coherence comprises three components, e.g. comprehensibility (belief that things happen in a predictable fashion), manageability (belief that the resources necessary to take care of things are available), and meaningfulness (belief that things in life are a source of satisfaction) [31]. The original questionnaire developed by Antonovsky was adapted to and validated in German [32, 33]. Similar to our study, others also found an association between chronic stress and sense of coherence $[34,35]$ as well as physical and emotional wellbeing [36-41]. The BFS items social resonance, social potency and social dominance were assessed by the Giessen-Test, a deep-psychosocial personality test [42]. The dimension social resonance reflects an individual's self-rating of attractiveness and popularity. In our study, there was a significantly negative correlation between social resonance and chronic stress exposure. Thus, a person exposed to chronic stress was more likely to rate him-/herself as being, e.g. unattractive, unpopular, disregarded and criticized at work. This finding supports previous studies showing that negative social resonance was correlated to neuroticism [22] that in turn correlated with chronic stress exposure [40]. So far, the association between chronic stress exposure and social potency as well as social dominance has not been investigated before. The dimension social potency reflects an individual's readiness to socialize. In our study, there was a significantly positive correlation between social potency and chronic stress exposure. Thus, a person exposed to chronic stress was more likely to rate him-/herself as being, e.g. isolated, conscious in heterosexual contacts and little competitive. The dimension social dominance reflects an individual's self-awareness of being dominant or submissive. In our study, there was a significantly negative correlation between social dominance and chronic stress exposure. Thus, a person exposed to chronic stress was more likely to rate him-/herself as being, e.g. willingly dominant, impatient and involved in conflicts.

However, psychometric assessment of chronic stress is highly subjective. Accordingly, several attempts have been made to measure stress objectively. Objective assessment tools comprise, e.g. cortisol levels in serum, saliva or urine [43]. However, cortisol levels may fluctuate markedly depending on, e.g. the circadian rhythm [44], nicotine [45] and alcohol consumption [46], food intake [47] and exercising [48]. Thus, the high variability of the HPA axis activity makes it difficult to draw conclusions from random single cortisol levels but would 
require repeated sampling across longer periods of time [43]. In future, another option for chronic stress exposure might be cortisol level measurement in hair. Yet, age- and sex-specific validation of this technique will be mandatory prior to its clinical use. Besides cortisol level measurements, no other objective parameters have been established for chronic stress assessment.

In our study, 14 objective BFS items significantly correlated with chronic stress exposure assessed by TICSSSCS: (1) systolic blood pressure, handgrip strength ((2) left, (3) right, (4) both hands), (5) vital capacity, (6) body weight and (7) height, (8) body composition ((9) active cell mass, (10) body water and (11) lean body mass), (12) performance time, (13) tapping, and (14) BFA, respectively. However, as most items are not independent variables we focused on handgrip strength, performance and tapping time.

Handgrip strenghth was significantly negatively correlated with chronic stress exposure in our study. So far, only few studies focused on muscle strength and chronic stress $[49,50]$. For example, in veterans suffering from posttraumatic stress disorder handgrip strenghth was fatigable more rapidly and force fluctuations increased at a greater rate during low-intensity contractions in comparison to healthy controls [50]. An explanation for the greater muscle fatigability in chronically stressed people might be an imbalance in both, excitatory and inhibitory neuro-signaling pathways during motor tasks, that may lead to impairments in motor performance [50-52]. In contrast, a study in postmenopausal women did not find a correlation between muscle strenghth and perceived stress $[49,53]$. However, our finding must be interpreted with caution as the correlation size was small. Cardiovascular performance including performance time was assessed at submaximal stress level to test the individual fitness level and pre-condition for physical endurance performance, respectively. During the test, the subject was requested to perform 20 squats as fast as possible. In our study, there was significantly positive correlation between chronic stress exposure and performance time indicating that chronically stressed idnividuals required more time to perform the task. The tapping test assesses psychomotoric speed by asking the participant to tap with a pen as fast as possible for $2 \mathrm{~min}$. It may be used as a marker for motivation [54]. In our study, chronic stress exposition was significantly negatively correlated with mean tapping frequency indicating that general motivation was lower in stressed than in non-stressed individuals. These observations fit into the central concept of psychosomatic medicine that is that mind and body are integral aspects of all human function and that illness or alterations in physical functioning may be a consequence of stress. As several BFS items were correlated to chronic stress exposure we aimed to construct a sum score in order to represent chronic stress exposure by a single new parameter integrating subjective and also objective parameters. As some BFS items such as body composition, vital capacity, body weight and height and BFA can only be interpreted in the context of age or sex, respectively, we did not include them in our model. Due to the low prevalence of hypertension in BeCS-14 we also chose to exclude blood pressure in our model. We were able to construct a sum score out of three BFS items (SOC_L9, complaint questionnaire: physical and emotional wellbeing) that represented chronic stress exposure best within our complex generic BFS/BFA assessment tool. However, we still need to primarily rely on subjective items.

Chronic stress exposure has been frequently linked to the development of NCD such as cardiovascular diseases [3] and Alzheimer disease [55]. Furthermore, depression and burnout syndrome $[24,56]$, sleeping disorders [6] chronic pain [7], disturbances of food intake and body weight [57], and immune dysregulation/immunosenescence [58, 59] were found to be more commen in people with high chronic stress exposure. The impact of chronic stress was also reflected on the molecular and cellular level indicating accelerated aging [60-63]. As our complex generic BFS/BFA assessment tool reflects physical, mental-emotional and social functioning as well as chronic stress exposure our observation that higher chronic stress exposure was associated with bio-functional pro-aging (less vitality) perfectly fits to previous studies showing a negative impact of chronic stress exposure on various body cells, organs and systems.

Our study clearly had some limitations. First, recruitement bias cannot be excluded as advertisement for the study was mainly performed in the "medical" environment of the Inselspital Bern. Secondly, we did not randomize participants according to, e.g. age and sex. Thirdly, our complex generic BFS/BFA assessment tool was strictly non-invasive therefore we were not able to adjust our results to e.g., saliva cortisol levels. Lastly, the study design was cross-sectional so we could not rule out intra-personal day-to-day deviations within TICS.

On the other hand, our complex BFS/BFA assessment tool has been shown to be reliable [8].

\section{Conclusion}

We recently fitted our complex generic BFS/BFA assessment tool into a theoretical model incorporating both, the ICF and AHA concept, resulting in a complex AHA assessment diagnostic tool [8] meeting the EIP-AHA requirements for a diagnostic AHA instrument [9]. Chronic stress is known to be one major contributor to develop NCD. We successfully demonstrated that our complex BFS/BFA assessment tool reflects chronic stress exposure by subjective as well as objective BFS items. 
The sum score out of three subjective BFS items was the best parameter to reflect chronic stress exposure. Our findings support the applicability of the BFS/BFA assessment tool in all areas of a patient-, customer- or need-orientated health care setting, e.g., in health promotion and prevention of NCDs, in therapy and rehabilitation of chronic health conditions and multi-morbidity.

\section{Abbreviations}

BeCS-14: Bern Cohort Study 2014; BFA: Bio-functional age; BFS: Bio-functional status; CA: Chronological age; EIP-AHA: European Innovation Partnership on Active and Healthy Ageing; ICF: International Classification of Functioning, Disability and Health; NCD: Non-communicable disease; SOC_L9: Sense of coherence test; TICS: Trier Inventory for the Assessment of Chronic Stress; TICS-SSCS: Standardised screening scale for chronic stress (part of TICS)

\section{Acknowledgements}

The authors would like to thank J. D. Wanner (JDW) and D. Gafner, study nurses, for her administrative assistance during the study. Also, the authors are thankful to the medical students for conducting the assessments: N. Ammann, S. Berger, S. Blum, G. Capaldo, J. Füri, M. Gahl, V. Heller, L. Kramer, M. Moser, J. Siegenthaler, M. von Bergen, J. von Holzen and V. Widmer.

\section{Funding}

The study was supported by an unrestricted grant by Merck Sharp \& Dohme Corp. and Burgergemeinde Bern.

\section{Availability of data and materials}

Data is not available as they are used for further analysis and follow-up studies.

\section{Authors' contributions \\ MA and $\mathrm{LH}$ were responsible for the practical assessments described in section 2.3. The statistician NB supervised MA during statistical analysis. FM was responsible for data bank organization. DP invented the BFS/BFA assessment tool and supported data interpretation. $\mathrm{LH}$ and MW helped with literature search. PS was responsible for the whole study protocol, ethic committee approval, finances, supervision of the doctoral students, data interpretation, literature search and writing the manuscript. All authors read and approved the final manuscript.}

\section{Ethics approval and consent to participate}

The study protocol was approved by the Cantonal Ethics Committee Bern (Ref.-Nr. KEK-BE: 023112), and written informed consent was obtained from each participant.

\section{Consent for publication}

All authors agree to publication and adhere to the journal's requirements.

\section{Competing interests}

P. Stute, M. von Wolff, N. Bitterlich, L. Hollenstein and M. Anker declare to have no conflict of interest in context of this manuscript. F. Meissner is managing director of vital.services and D. Poethig is member of the scientific board of vital.services, which provides the technology for BFS measuring. F. Meissner has no involvements that might raise the question of bias in the work reported or in the conclusions, implications, or opinions stated.

\section{Publisher's Note}

Springer Nature remains neutral with regard to jurisdictional claims in published maps and institutional affiliations.

\section{Author details}

${ }^{1}$ Department of Gynecologic Endocrinology and Reproductive Medicine, University Clinic of Obstetrics and Gynecology, Inselspital Bern, Effingerstrasse 102, 3010 Bern, Switzerland. 'Departement of Visceral and General Surgery, Spital Thun STS, Thun, AG, Switzerland. ${ }^{3}$ Departement of Internal Medicine, Spital Oberengadin, Samedan, Switzerland. ${ }^{4}$ Medizin \& Service $\mathrm{GmbH}$, Chemnitz, Germany. ${ }^{5}$ vital.services GmbH, Im GerontoLabEurope, Leipzig,
Germany. ${ }^{6}$ European Association on Vitality and Active Aging eVAA e.V, Leipzig, Germany.

Received: 26 October 2018 Accepted: 28 January 2019

Published online: 12 February 2019

\section{References}

1. Kuh D, et al. A life course approach to healthy ageing. Oxford: Oxford University Press; 2014.

2. Petrowski $\mathrm{K}$, et al. Factor structure and psychometric properties of the trier inventory for chronic stress (TICS) in a representative German sample. BMC Med Res Methodol. 2012;12:42.

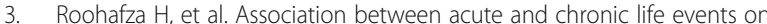
acute coronary syndrome: a case-control study. J Cardiovasc Nurs. 2010; 25(5):E1-7.

4. Schüler J, Dietz F. Kurzlehrbuch Medizinische Psychologie und Soziologie. Stuttgart: Thieme; 2004.

5. Buddberg C, et al. Psychophysiologie, in Psychosoziale Medizin. Berlin: Springer; 2004.

6. Schulz P, Hellhammer J, Schlotz W. Occupational stress, social stress and sleep quality: differential effects in consideration of age, worry disposition, and health. Zeitschrift für Gesundheitspsychologie; 2003.

7. Ehrstrom S, et al. Chronic stress in women with localised provoked vulvodynia. J Psychosom Obstet Gynaecol. 2009:30(1):73-9.

8. Stute $P$, et al. Measuring active and healthy ageing: applying a generic interdisciplinary assessment model incorporating ICF. J Nutr Health Aging. 2017;21(9):1002-9.

9. Bousquet J, et al. Operational definition of active and healthy aging (AHA): the European innovation partnership (EIP) on AHA reference site questionnaire: Montpellier October 20-21, 2014, Lisbon July 2, 2015. J Am Med Dir Assoc. 2015;16(12):1020-6.

10. Rüesch $P$, Bartlomé $P$, Huber $C$. Evaluation von Messinstrumenten für den strategischen Bereich 'psychische Gesundheit/Stress'. Winterthur: Fachstelle Gesundheitswissenschaften, Zürcher Hochschule Winterthur (Departement Gesundheit); 2006

11. Hamilton M. A rating scale for depression. J Neurol Neurosurg Psychiatry. 1960;23:56-62.

12. Bullinger M, Kirchberger I, Ware J. Der deutsche SF-36 Health Survey. Übersetzung und psychometrische Testung eines krankheitsübergreifenden Instrumentes zur Erfassung der gesundheitsbezogenen Lebensqualität Zeitschrift fuer Gesundheitswissenschaften. 1995;1:21-36.

13. Schulz P, Schlotz W, Becker P. Trierer Inventar zum chronischen Stress (TICS). Göttingen: Hogrefe; 2004.

14. Ardelt-Gattinger $\mathrm{E}$, Meindl M. AD-EVA. Interdisziplinäres Testsystem zur Diagnostik und Evaluation bei Adipositas und anderen durch Ess- und Bewegungsverhalten beeinflussbaren Krankheiten. Bern: Huber; 2010.

15. Zenz $\mathrm{H}$, Bischoff $\mathrm{C}$, Hrabal V. Patiententheorienfragebogen (PATEF). Handanweisung. Göttingen: Hogrefe; 1996.

16. Molnar M, Haiden C, Geißler-Gruber B. IMPULS-Broschüre und IMPULS-Test. In: Betriebliche Analyse der Arbeitsbedingungen. Wien: AUVA, AK, ÖGB, WKÖ (Hg.); 2012.

17. Camm AJ, Malik M, Bigger JT, Breithardt G, Cerutti S, Cohen R, Coumel P, Fallen E, Kennedy H, Kleiger RE, Lombardi F. Heart rate variability: standards of measurement, physiological interpretation and clinical use. Task Force of the European Society of Cardiology and the North American Society of Pacing and Electrophysiology. Circulation. 1996;93(5):1043-65.

18. Kalbe $\mathrm{E}$, et al. Das Inventar zur Gedächtnisdiagnostik: Vorstellung der endgültigen Version. Akt Neurol. 2006;33(S 1):301.

19. Poethig D. Experimental development of a clinical diagnostic model objectifying bio-functional age(ing) of human being. Habilitation thesis (dt.). German: National Library Leipzig; 1984. http://d-nb.info/850613108

20. Ries W, Poethig D. Chronological and biological age - a new method to measure healthy aging. Exp Gerontol. 1984;19(3):211-6.

21. Dean W. Biological aging measurement: clinical applications. The German test battery, university Leipzig, 175-87. Los Angeles: The Center for Bio Gerontology; 1988.

22. Meissner-Poethig D, Michalak U. Vitalitaet und aerztliche Intervention. Vitalitaetsdiagnostik: Grundlagen - Angebote - Konsequenzen: Hippokrates-Verlag; 1997.

23. Schulz P, Schlotz W, Becker P. Trierer Inventar zum chronischen Streß (TICS). Göttingen: Hogrefe-Verlag; 2004. 
24. Hapke U, et al. Chronic stress among adults in Germany: results of the German Health Interview and Examination Survey for Adults (DEGS1). Bundesgesundheitsblatt Gesundheitsforschung Gesundheitsschutz. 2013;56(5-6):749-54.

25. Meissner-Poethig D. Die Gesundheit der Frau: Klimakterium, Vitalität und Hormonsubstitution-Ergebnisse einer funktionsdiagnostischen Pilotstudie. Journal für Menopause. 2003;10(3):20-7.

26. Freude $\mathrm{G}$, et al. Predictors of the discrepancy between calendar and biological age. Occup Med (Lond). 2010;60(1):21-8.

27. Schwarzer R. Stress, angst und Handlungsregulation. Stuttgart: Kohlhammer Verlag; 1993.

28. Cohen S, Kamarck T, Mermelstein R. A global measure of perceived stress. J Soc Health Soc Behav. 1983;24(4):385-96.

29. Schulz, P., L.J. Jansen, and W. Schlotz, Stressreaktivität: Theoretisches Konzept und Messung. 2005 . https://doi.org/10.1026/0012-1924.51.3.124,.

30. Fliege, $H_{\text {., }}$ et al., Validierung des "Perceived Stress Questionnaire"(PSQ) an einer deutschen Stichprobe. 2001. https://doi.org/10.1026//0012-1924.47.3.142.

31. Antonovsky A. Unraveling the mystery of health. How people manage stress and stay well. San Francisco: Jossey-Bass; 1987. p. 189-94.

32. Schumacher J, et al. The Antonovsky Sense of Coherence Scale. Test statistical evaluation of a representative population sample and construction of a brief scale. Psychother Psychosom Med Psychol. 2000;50(12):472-82

33. Singer S, Brähler E. Die "sense of coherence scale" (Testhandbuch zur deutschen version). Göttingen: Vandenhoeck \& Ruprecht; 2007.

34. Wild $K$, et al. Strategies against burnout and anxiety in medical education--implementation and evaluation of a new course on relaxation techniques (Relacs) for medical students. PLoS One. 2014; 9(12):e114967.

35. Zirke N, et al. Antonovsky's sense of coherence in psychosomatic patients - a contribution to construct validation. Psychosoc Med. 2007:4:Doc03.

36. Hautzinger $\mathrm{M}$, et al. Beck- Depressions-Inventar (BDI): Bearbeitung der deutschen Ausgabe. Testhandbuch. Bern: Hans Huber; 1994.

37. Fahrenberg J. Die Freiburger Beschwerdenliste (FBL). Form FBL-G und revidierte form FBL-R. Handanweisung. Göttingen: Hogrefe; 1994.

38. Fahrenberg J, Hampel R, Selg H. Das Freiburger Persönlichkeitsinventar FPI. Revidierte Fassung FPI-R und teilweise geänderte Fassung FPI-A1. Handanweisung. Göttingen: Hogrefe; 1994.

39. Franke G. Die symptom-Checkliste von Derogatis - deutsche version - (SCL-90-R). Manual. Beltz test GmbH. Göttingen: Hogrefe; 1995.

40. Becker $P$, Schulz P, Schlotz W. Persönlichkeit, chronischer Stress und körperliche Gesundheit. Zeitschrift fuer Gesundheitspsychologie. 2004;12(1):11-23.

41. Schulz P, Schlotz W. Das Trierer Inventar zur Erfassung von chronischem Stress - Version 2 (TICS 2). Trierer Psychologische Berichte. 2002;29(2).

42. Beckmann D, Brähler E, Richter H-E. Der Gießen-Test (GT). Vol. 4. erweiterte und überarbeitete Auflage mit Neustandardisierung 1990. Bern: Huber; 1991.

43. Stalder T, Kirschbaum C. Analysis of cortisol in hair--state of the art and future directions. Brain Behav Immun. 2012;26(7):1019-29.

44. Weitzman ED, et al. Twenty-four hour pattern of the episodic secretion of cortisol in normal subjects. J Clin Endocrinol Metab. 1971;33(1):14-22.

45. Steptoe A, Ussher M. Smoking, cortisol and nicotine. Int J Psychophysiol. 2006:59(3):228-35.

46. Mendelson JH, Stein S. Serum cortisol levels in alcoholic and nonalcoholic subjects during experimentally induced ethanol intoxication. Psychosom Med. 1966;28(4):616-26.

47. Gibson $\mathrm{EL}$, et al. Increased salivary cortisol reliably induced by a protein-rich midday meal. Psychosom Med. 1999;61(2):214-24.

48. Galbo H. Endocrinology and metabolism in exercise. Curr Probl Clin Biochem. 1982;11:26-44.

49. Karelis AD, et al. Psychosocial correlates of cardiorespiratory fitness and muscle strength in overweight and obese post-menopausal women: a MONET study. J Sports Sci. 2008;26(9):935-40.

50. Keller-Ross ML, et al. Muscle fatigability and control of force in men with posttraumatic stress disorder. Med Sci Sports Exerc. 2014;46(7):1302-13.

51. Rossi S, et al. Dysfunctions of cortical excitability in drug-naive posttraumatic stress disorder patients. Biol Psychiatry. 2009;66(1):54-61.

52. Falconer $\mathrm{E}$, et al. The neural networks of inhibitory control in posttraumatic stress disorder. J Psychiatry Neurosci. 2008;33(5):413-22.

53. Cohen S, Kamarck T, Mermelstein R. A global measure of perceived stress. J Health Soc Behav. 1983;24(4):385-96.
54. Poethig D, et al. Experimentelle Untersuchungen zum psychomotorischen Grundtempo im Alternsgang. Medizin und Sport. 1985:25(3):73-8.

55. Machado A, et al. Chronic stress as a risk factor for Alzheimer's disease. Rev Neurosci. 2014;25(6):785-804.

56. Swaab DF, Bao AM, Lucassen PJ. The stress system in the human brain in depression and neurodegeneration. Ageing Res Rev. 2005:4(2):141-94.

57. McEwen BS. Physiology and neurobiology of stress and adaptation: central role of the brain. Physiol Rev. 2007;87(3):873-904.

58. Bauer ME. Chronic stress and immunosenescence: a review. Neuroimmunomodulation. 2008;15(4-6):241-50.

59. Bauer ME, Jeckel CM, Luz C. The role of stress factors during aging of the immune system. Ann N Y Acad Sci. 2009;1153:139-52.

60. Prenderville $\mathrm{JA}$, et al. Adding fuel to the fire: the impact of stress on the ageing brain. Trends Neurosci. 2015;38(1):13-25.

61. Monaghan P. Organismal stress, telomeres and life histories. J Exp Biol. 2014 217(Pt 1):57-66.

62. Oliveira BS, et al. Systematic review of the association between chronic social stress and telomere length: a life course perspective. Ageing Res Rev. 2016;26:37-52.

63. Maestripieri D, Hoffman CL. Chronic stress, allostatic load, and aging in nonhuman primates. Dev Psychopathol. 2011;23(4):1187-95.

\section{Ready to submit your research? Choose BMC and benefit from:}

- fast, convenient online submission

- thorough peer review by experienced researchers in your field

- rapid publication on acceptance

- support for research data, including large and complex data types

- gold Open Access which fosters wider collaboration and increased citations

- maximum visibility for your research: over $100 \mathrm{M}$ website views per year

At $\mathrm{BMC}$, research is always in progress.

Learn more biomedcentral.com/submissions 